\title{
Life Roles and College Life: Exploring Experiences of International Female Students in Higher Education
}

\author{
Beatrice Asante Somuah \\ College of Distance Education, \\ University of Cape Coast Cape Coast, Ghana
}

Doi: 10.36941/jesr-2020-0025

\begin{abstract}
Studies have identified that women enter higher learning institutions for personal enrichment and lifelong education. In spite of these benefits, societal perception and traditional roles affect women's participation in formal education. This qualitative study sought to explore the experiences of female students on how they deal with their lifecycle roles as they access higher education outside their home countries. The study was conducted in a Kenyan university using seven graduate international female students. These participants were purposively selected for face-to-face interviews. Content analysis was used to analyse data based on similarities and differences. It was revealed that the female faced challenges such as psychological stress, financial problems and time constraints. They managed these roles through support from family and friends as well as the use of self-motivation strategies. It was therefore recommended that interventions geared towards the needs of these female students are developed by institutions who admit international students.
\end{abstract}

Keywords: International graduate female students, Multiple roles, Higher education, College experiences, Coping strategies

\section{Introduction}

Globally, the education sector has seen a tremendous increase in technological and international collaboration resulting in increased investment by governments, individuals and institutions towards quality education, training and lifelong learning that meet international standards (Tight, 2012). The internationalisation of higher education has seen a lot of students moving from one country to another to pursue higher education. Among these students, there are a good number of female students who patronise institutions outside their home countries for a number of reasons. These students who come with diverse background can be considered as a group with unique needs, experiences and goals (Panacci, 2015). Studies have shown that apart from the core needs of satisfying personal and academic development, most of these students are pursuing higher education as a result of the current surge for knowledge-based economies which is characterised by the need for skilled expertise in the labour market (Palameta \& Zhang as cited in Panacci, 2015; Bosch, 2013; Mudhovozi, 2011). Fairchild (2003) further indicated that "rather than being a life-encompassing and identitybuilding experience", for international students, higher education is "one activity among many others they participate to meet specific needs" (p. 12). 


\section{Women and Higher Education}

Picking his perspectives from earnings, Johnston (2004) reiterated that higher education had both individual and societal benefits. According to Johnson (2004), individual benefits may include higher wages which results in becoming healthier and enjoying greater life fulfilments, while the societal benefits are seen through higher national income, increased national health rates and better societal functioning. Murray (2009) added that individuals who go through higher education seem to be more tolerant, resilient and also enjoy expanded social networks.

Despite these benefits, women entering higher education (both full time and part time) especially at the graduate levels tend to be older and are therefore more likely to have children and other family commitments (Bosch, 2013). Particularly, the female student may have multiple roles and responsibilities that carry considerable emotional, practical and financial burdens (Edwards as cited in Lowe \& Gayle, 2007). According to Forrest and Peterson, the identities of these female students are not defined primarily by their role as students, but are formed by an intersection of all the roles they assume while living out their daily lives (Marsman, 2014). Therefore, whereas many of these female students experience psychological distress related to balancing family and academic roles, others benefit from managing these multiple roles.

A study by Quimby and O'Brien (2006) conducted among 209 female undergraduate students with children looked at factors that influenced their psychological well-being. The researchers found that secure attachment, parental support, student self-efficacy and social support contributed to the prediction of psychological distress (38\%), self-esteem (54\%), and life satisfaction (35\%). Recommendations were therefore made towards enhancing counselling services for female students (Quimby \& O'Brien, 2006). In a similar study, Sallee (2015) interviewed 18 student parents (12 women and 6 men) who were also employees of university and college campuses. Participants were selected from 10 universities in the United States. The study aimed at exploring how student parents navigated through their academic, familial and professional responsibilities, and considered the strategies the respondents used to meet the demands of these multiple roles (Salle, 2015). The researcher found that though participants prioritized their roles as parents above all other roles, they valued their roles as students and made the necessary efforts to meet all expectations associated with each role demand.

Though maintaining multiple roles can be beneficial to a female student, care must be taken to minimize role conflict which can result from these roles (Dalla, MoulikGupta, Lopez, \& Jones, 2006). Research shows that women who must integrate the role of student with other roles have a challenging task since these disproportionate responsibilities demand both time and energy (Dalla et al., 2006). A review by Tight (2012) found that majority of the studies on students' experiences in higher education had focused on full-time undergraduate students as they form the core of student body of most universities. Few studies focused on the experiences of graduate students, more especially female students studying outside their countries of origin. The current study explored the experiences of graduate international female students in a university in Kenya.

\section{Purpose of the Study}

This study explored the life roles and college experiences of graduate international female students at a Kenyan university. Specific questions that guided the conduct of the study were: a) what life roles do the graduate international female students play while in college? b) what motivates graduate international female students in their studies? c) what challenges do graduate international female students experience? and d) how do they cope with the challenges?

\section{Theoretical Framework}

The study was supported by two key theories namely; role conflict theory (Biddle, 1979) and moral 
development theory (Gilligan, 1982). These theories seemed appropriate because females usually assume several roles such as being a mother, partner, employee and a student and experience situations where the roles they play conflict with each other. When such situations crop up, the female would have to make moral decisions as to which of the roles needs to be prioritised. Biddle (1979) further indicated that role conflicts are most probable to occur as these females attempt to fulfil and balance their multiple roles. Goode (1960) introduced the term "role strain" to describe the resulting strain that occurs when an individual makes effort to meet the demands of multiple roles.

In addition, Sieber (1974) stressed that role overload and role conflict are two situations that can contribute to role strain. Role overload usually occurs when individuals are faced with time constraints in relation to the various roles they must fulfil. That is, if an individual had too many roles to perform, such that the person would have to perform some roles at the expense of others, then role overload had occurred. Role conflict on the other hand arises when the demands of each role seemed different despite finding solutions to time constraints (Sieber, 1974). Sieber (1974) further argued that that in spite of the fact that performing different roles almost always exposes one to an increased role conflict, some people would as a result of their personalities desire to take on multiple roles.

Gilligan (1982) on the other hand, took a look at the moral development of females in relation to their roles. Gilligan's theory asserted that relationship, care and responsibility form the basis of females' moral decision making and the manner in which they understand, evaluate and mediate conflicts between roles. Gilligan structured the theory around three levels with two interwoven transitions between the levels. The first level which is orientation to individual survival begins the moral development in most females. Females at this level can experience transitions ranging from selfishness or self-centredness to assuming full responsibility of roles (Gilligan, 1982). The second level of the theory which is goodness as self-sacrifice is the stage where females in their bid to seek social acceptance and retain their connection with others, try to conform to traditional female gender values with the aim of avoiding the creation of conflict with others (Gilligan, 1982). An example is where a female student who is also a mother delays the submission of her research report in order to attend to the needs of her child preparing to write a final examination at the primary school to ensure that the child goes through the examination successfully. Though her responsibility as a mother conflicts with her role as a student, being a parent seems more important to her at this stage of moral development. This issue bordering on morality may push her to see the needs of the child in compliance with the expectations of the society regarding her gender roles.

At level three, Gilligan explained that decisions and judgements of actions of females are guided by principles that help them to avoid violence and prevent them from harming themselves or others. At this point, the female develops some level of self-respect that empowers her to create a balance between meeting her needs and that of others. Another characteristic exhibited by most females in reaching level three is the control they have over making decisions based on merits and individual needs rather than on the expectations of the society and gender-based norms (Gilligan, 1982). Gilligan however noted that, most females remain at the second level of the moral development where the decisions they make are influenced by gender norms of their individual societies all in an attempt to avoid conflict and to gain acceptance among the members. The role conflict and the moral development theories therefore offer some explanation to why some females struggle to combine motherhood and other responsibilities with studies as argued by researchers (Somuah, Itegi \& Kariuki, 2018; Mudhovozi, 2011; Pare, 2009; White, 2008). These theories were explored to serve as theoretical explanations for understanding the experiences of international graduate female students who studied at a Kenyan university. These female students were identified with multiple roles (e.g., employee, mother, student, religious and community member) and thereby exhibited a range of role identities but the importance they assigned to each of these identities varied in relation to how each individual female perceived the demand of each role (Carlson \& Kacmar as cited in Powell \& Greenhaus, 2010). 


\section{Methodology}

\subsection{Research Design}

The study adopted a qualitative orientation using the hermeneutic phenomenological research design to explore the lived experiences of the participants. This approach was seen as most appropriate as it allowed the researcher to understand issues from everyday knowledge and perceptions of specific respondents who had lived experiences of the phenomenon under study (Lindgren \& Kehoe, 1981 cited in Groenewald, 2004; Creswell, 2008). This approach was suitable for the study as researcher was interested in developing a more in depth understanding of the roles of female students through the shared experiences of graduate female students studying outside their countries of origin.

\subsection{Participants' Selection and Demographics}

Participants were drawn from female students pursuing various graduate programmes in a university in Kenya. Participants were selected from the list of international graduate students from the Centre for International Programmes and Collaborations of a Kenyan university. The participants were recruited based on this set of criteria; (i) must be graduate student enrolled on a master or doctorate programme, (ii) must have at least one child (iii) must be an African studying outside the home country (to ensure results do not digress as female students from other continents were likely to experience different role demarcations). A total of seven graduate female students who met these criteria were purposively selected. They were nationals from Eastern and Western African countries which included Tanzania, Zimbabwe, Zambia, Ghana and Nigeria and were pursing programmes in Fashion Designing, History, Education, Sports and Health, Diet and Nutrition, and Hospitality and Tourism Management. The participants were aged between 35 and 50 years and had between one and four children with the youngest child at 2 and oldest at 25 as depicted in Table 1.

Table 1: Participant Demographics

\begin{tabular}{cccc}
\hline List of Participants & Programme & Age & Number of Children \\
\hline Participant 1 & Doctorate & 48 & 3 \\
Participant 2 & Doctorate & 49 & 4 \\
Participant 3 & Masters & 35 & $\mathbf{2}$ \\
Participant 4 & Masters & 36 & 2 \\
Participant 5 & Doctorate & 40 & 2 \\
Participant 6 & Masters & 48 & $\mathbf{2}$ \\
Participant 7 & Doctorate & 50 & 3 \\
\hline
\end{tabular}

Source: Field Data, 2019

A semi-structured interview guide which was flexible and allowed follow up questions for further probing was used (Creswell, 2014; Flick, 2014). To ensure trustworthiness, the researcher used pretesting, peer debriefing and member check to enhance credibility of results (Lincoln \& Guba, 1985; Creswell, 2008). The interview guide was pilot-tested with two international graduate female students who did not take part in the main study. Data were collected through face-to-face interviews with the seven participants individually at their places of residence. Brief interview notes were taken and the conversations were also recorded using an audio tape with the consent of the participants. They were also informed of their right to voluntarily withdraw at any time during the research. With the help of other researchers, the peer debriefing approach was used to seek opinions and comments on all stages of the research process. The researcher took a great caution during the analysis of data to minimise biases by using member check. This was done by sharing the findings with participants 
to seek their feedback and confirm that the results portrayed their shared experiences. Such feedback was finally incorporated into the study. Each interview session took 35 to 40 minutes per participant and coded names were used to protect the identity of the participants.

\subsection{Data Analysis}

All the audio taped interview conversations were transcribed. Every line was read carefully and data was coded. Content analysis was used to analyse data based on similarities and differences (Babbie \& Mouton, 2001). This was followed by the identification and categorisation of patterns to bring out core meanings and consistencies. Thereafter, central themes were identified and responses were then grouped within the themes and supported with some verbatim responses by participants (Creswell, 2012).

\section{Findings}

Themes that emerged from this qualitative study included managing family roles and social roles, financial constraints, motives for studying outside the home countries, benefits and challenges of dealing with multiple roles and coping strategies adopted.

\subsection{Family Roles}

This theme had two sub-themes which included childcare and marital responsibilities. Participants' views were sought on both themes and results presented below:

Childcare: All the participants were married and had children (aged between three and 25 years) which were distinctive of graduate female students. Some of the participants indicated that they were depending on support of house helps, spouses and relatives to take care of the children. Others however reiterated that due to the age of their children and their emotional disposition as mothers, they brought their children along with them. These were statements to support this view:

I have a supportive spouse and house help who are taking care of my three girls but there were occasions when I felt I should have been at home to perform certain activities. For instance, my last girl always wanted to be fed, so during meal times I am attempted to make a phone call to find out if she has been fed well. It can sometimes be a stressful situation as you seemed helpless (Participant 1).

I brought my four children to stay with me as I could not bear the emotional stress of leaving them behind due to the nature of the job my spouse does. I had put two of them in a boarding school to allow me time to concentrate on my studies (Participant 2).

My son was a year old when I gained admission. I brought him along as I did not want to forego this opportunity. Now, I had to combine childcare roles with my studies (Participant 5).

My first daughter was expecting a baby and since it was her first time, I felt it was good if she had the baby in Kenya. I am now taking care of my studies, my daughter and a newly born baby (Participant 7).

Marital roles: The participants confirmed they had spouses and were trying to maintain their married lives. They reported that they had supportive spouses who understood their current status as students. However, some added these comments:

I know my husband understands and supports me but sometimes I tend to feel as I am unable to play my role fully as a wife to satisfy his physical and sexual needs, the chances of him seeing another woman as a result of my long absence from home becomes very high. But we are trusting God to take care! (Participant 3).

Maybe I am lucky because I gained admission with my husband so we live together now. I am able to perform my responsibilities as a wife but I need to manage my time well to study effectively (Participant 4). 


\subsection{Social Roles}

Some participants indicated that they played active role in social activities such as holding positions in the churches on campus and in town while in school. With respect to their traditional roles, they indicated that they played partial roles by giving suggestions through phone calls as relatives went through ceremonies such as weddings, births and burials as indicated by the statements of these participants:

I am a fashion designer and on occasions such as wedding and naming ceremonies, I used to play a leading role. As a student, what I can do now is to give suggestions through phone calls and contribute financially towards these celebrations (Participant 1).

During burials and weddings, I sometimes travel home to take part in the planning and the celebration if I am less busy with my studies. Most of the times, I only send my monetary contributions (Participant 3). Though we are students, we are still part of the extended family back home. When we lose a family member, I make phone calls to show my sympathy or ask my husband and other female relatives to represent me and perform the traditional rites expected of me (Participant 5).

\subsection{Financial Roles}

The financial responsibilities of the participants were seen in areas such as payment of fees, taking care of their needs and that of their family when it became necessary. Most of the participants (80\%) indicated that they were granted study leave with pay from their employers. In addition, some of them $(20 \%)$ indicated they were enjoying sponsorship from their employers. This was supported with the under listed statements:

My finances are not enough for my needs and that of my children who are also schooling here. My spouse and siblings always send some help when the need arises (Participant 2).

I am caring for three children of my late brother in addition to my own children. It increases my financial obligations (Participant 3).

Though we are on study leave, we have to manage our resources well to be able to pay for our education, food, accommodation, health needs and send enough money home to cater for the needs of our children and in-laws (Participant 4).

I enjoyed full sponsorship from my employers so I am financially good as far as my academic and personal needs are concerned. But sometimes I need to send some money home to help my spouse take care of the children and fulfil other family obligations (Participant 7).

\subsection{Motives for Studying Outside Home Country}

Most of the participants (85.7\%) reported that they chose to come to study in Kenya because the university offered programmes which were more suitable to their areas of specialisation and were economically moderate when compared with other universities offering similar programmes elsewhere. One participant further indicated that she had taken both diploma and undergraduate professional courses in Kenya and therefore felt it was better to continue with a master programme as well. The following were some of the further explanations given by the participants:

As a mother and a wife, I need to consider the financial options involved in furthering my education and this university was the best option among others (Participant 1).

I wanted an exposure in a different academic environment and it adds some quality to my curriculum vitae (Participant 2).

I choose to be in this university because apart from my inclination to study in an African university, the courses mounted in my area of specialisation were very attractive (Participant 5).

Studying away from home gives me space and time to concentrate on my studies so that I can complete within schedule and return home. There are a lot of distractions that would have delayed my studies in a home university which is somehow minimal here (Participant 7). 


\title{
6.5 Benefits of Combining Roles
}

Most of the participants claimed that performing other roles in addition to being a graduate student serves as a motivation to work harder to satisfy their personal and academic goals, career progression and professional goals. The theme was supported with these vignettes which outlined the testimonies of some participants.

Academic and personal goals: Most of the participants reported that pursuing graduate studies would satisfy an inner desire and fulfil a family goal. These statements from three of the participants attested to this view:

\begin{abstract}
My children will be motivated to study hard as they see me progressing academically and I will be in a better position to provide academic counselling to my family (Participant 1).

Getting a doctorate degree was my academic goal as I was always encouraged by my teachers to climb higher on the academic ladder. It is also a way to serve as a role model to my children and my siblings (Participant 3).

I will become more economically independent when I am able to finish my studies. It will give me the opportunity to support the family and also take major decisions concerning the education and security of my children and the extended family (Participant 5).
\end{abstract}

Career progression: Some of the participants reiterated that a certificate in graduate studies had become a minimum requirement at their workplaces. Therefore, they had no option but to pursue programmes to earn these certificates in order to progress on their careers. These statements supported this assertion:

My institution now requires a PhD as minimum qualification for teaching and research. I therefore had no option than to pursue a doctorate degree to enable me secure my appointment (Participant 2).

I hope with a master degree, I will be able to secure an appointment in a university in my home country.

This will be a good career progression as a secondary school teacher (Participant 6)

Professional goals: This sub-theme looked at the professional skills to be acquired by participants as they pursued their graduate studies. One participant had this to say:

I run a consultancy services which require that we engage others in bidding for projects. With my expertise, my studies are going to boost my confidence and enable me manage my business in a professional manner (Participant 3).

\subsection{Constraints to Multiple Roles}

A theme that emerged from the study was situations that created conflicts between roles as graduate international female students. The participants noted some challenges that come with combining roles as psychological stress, institutional structures, financial problems, and time constraints for studies among others.

Psychological stress: The participants gave these comments to depict the psychological and emotional stress they sometimes went through as they combined their multifaceted responsibilities:

Trying to monitor my family from here can sometimes be very stressful. I only depend on phone calls and whatsapp chats to reach them which come with financial cost. There were occasions when I became so distressed about family issues that I found it difficult to concentrate on my studies (Participant 1). There were some occasions I could not concentrate on my academic work because I needed to help solve problems back home. I feel very much stressed on such situations and studying become just impossible (Participant 2).

My first girl was preparing for her final examination and as a mother, I felt very stressed and helpless as I am unable to give any help in such trying moment (Participant 6). 
Institutional structures: Almost all the participants raised the issue of lack of befitting accommodation for graduate students within the university campus. One of the participants commented:

Graduate students are not given accommodation on campus. Since I came along with my children, I needed to pay higher for a room large enough to accommodate us. Living in the community alone as a foreign student has its own disadvantages because it makes it difficult for you to connect with your colleagues (Participant 2).

Financial constraints: Though most of the participants said they were on study leave, the issue of additional burden of caring for dependants created a problem for them as reiterated in the statement below:

We are required to make full payment of our fees as international students. Combining this with other financial obligations sometimes create a lot of distress. It needs proper planning as we cannot access help from financial facilities in Kenya as international students (Participant 4).

Limited time for academic work: Providing the needs of children can be quite demanding especially for international female students who may not have the support of house helps or other relatives. This was likely to reduce the amount of time they can spend on their studies as indicated by these statements:

I usually have to make time to take care of my son. I send him to school and pick him up after school. He sometimes craves for my attention when I want to study (Participant 5).

Taking care of a new mother and a new born baby was really demanding as a student. The few weeks before and after the delivery of the baby was quite demanding and I couldn't do any effective academic work (Participant 7).

\subsection{Coping Strategies}

The focus of this theme was to find out the resources used by the participants to manage the competing roles. The sub-themes that emerged as strategies used to manage these multifaceted roles included family and friends' support, institutional support, time management skills and future benefits.

Support from family and friends: Most of the participants mentioned their spouses, siblings and friends as sources of support and encouragement. They reiterated that the support they receive from their family and friends helped them to deal with the roles as seen in these statements:

On one occasion when I had to travel home, my church member agreed to allow my girls stay with her till I returned (Participant 2).

My siblings are helping me to take care of my business at home under my directions. It's a big relief for me as I am able to concentrate on my academic work (Participant 3).

My sister is taking care of my children in my absence. Even though I give her financial support, it gives me peace of mind to do my studies (Participant 4).

Institutional support: The participants further indicated that the Directorate in charge of international students of the university supports them with the necessary information and logistics. Some of the participants had said that:

The staffs at the Directorate give me the audience I need anytime I face a situation which demands their advice or help. The meeting held by the Director allowed me to create social network with other international students. I think that if a more structured programme geared towards the needs of female students was developed, it would be very much helpful (Participant 1).

I would appreciate it if I had a chance of working for my department to enable me make some earnings financially as done in some departments and in some universities elsewhere (Participant 6). 
Good time management skills: Some of the participants related their abilities to cope with the various roles through the use of time management skills. Few participants made these observations:

I know it is difficult combining my roles as a mother and a student. I am required to be dedicated and committed to be able to succeed in both roles which are equally important to me (Participant 5).

I try to see to the needs of my children when I return from school. Then I wake up very early to work on my assignments (Participant 7).

Future benefits: The benefits that were perceived to be derived from the acquisition of a higher degree served as a consolation for some of the participants. For instance, one of the participants noted that:

I will not sacrifice my studies because I know my spouse and children will be very happy if I am able to complete my studies successfully. Even though I know it is quite demanding (Participant 3).

\section{Discussion}

It can be seen that the above findings were consistent with other studies that female students had to contend with multiple roles while in higher education no matter where they found themselves (Somuah, Itegi \& Kariuki, 2018; Marsman, 2014; Spilovoy, 2013; Bosch, 2013; Mudhovozi, 2011). The female students had relatives and spouses who cared for the children but their primary role as caregivers was seen to be displayed in various ways as reiterated by Ogletree (2014). Apart from using technological communication to monitor the welfare of their children back home, some graduate international female students came with their children to stay with them as they went through their studies.

As part of a larger extended family as seen in most African communities, the female students played various roles to ensure they maintained their relationship with the extended families (Mwangi, 2018). This is seen in the form of suggestions, financial contributions and notes of encouragements they sent during important family occasions. As asserted by Ruderman, Ohlott, Panzer and King (2002) involvement in these social roles create the opportunity for these female students to build stronger network with other members of their families as they live outside their countries.

Financial obligations of the participants were reported in varying degrees. While some enjoyed good financial positions, others had to depend on the support of relatives. As stressed by Bosch (2013) financial concerns continue to impact on many graduate female students. They were usually disturbed when it comes to the payment of their personal and college bills and caring for their dependents (Bosch, 2013; McKnight, 2015). A study by Adu-Yeboah (2011) on how female students experienced higher education confirmed the finding that one's economic background played a major role in influencing the financial decisions a female student made while embarking on a higher education. The findings of the current study however showed that most of the participants were doing well financially as they had enough to fulfil their basic needs. This was in line with the study by Bosch (2013) which found that the participants made efforts to live within their means to ensure that their financial obligations did not become an obstacle to their studies.

The study also revealed that the female students were motivated to do graduate studies because they derived various benefits which included personal, academic and professional skills among others. This was in line with the studies by Mwangi (2018), Bosch (2013) and Mudhovozi (2011) which found that female students enjoyed various benefits as being role models to their children as well as acquiring some sense of professional identities. It was revealed that these benefits served as a motivation for most of the participants to strive to succeed on their studies. The finding was in tandem with the study by McCune, Hounsell, Christie, Cree and Tett, (2010) which found that though both students were positively motivated, the students gave deeper and better judgments of how 
important and relevant studying in higher education meant to them. Some participants however, mentioned that they were sometimes saddled with some challenges such as psychological distress which emanated from roles they needed to manage through a distance, time constraints due to presence of their children around and financial problems (Marsman, 2014; Filipponi-Berardinelli, 2013; Quimby \& O’Brien, 2006).

The findings of this study further confirmed the views of other researchers that most female students valued the emotional and physical support they received from spouses and other family members (Hemmerich, 2014; Plageman, 2011). In addition, other coping strategies employed by the participants were seeking for help from the institution and friends. This was however in contrast with the findings of Keith (2007) and Mudhovozi (2011) where the participants reported neither using academic services nor peer support.

\section{Conclusions}

Though studying outside the home country, most graduate international female students were still constrained with multiple life roles as opposed to assumption that they were full-time students with little or no distractions. As complimented by O'Shea and Delahunty (2018), as institutions of higher education admit students with diverse backgrounds for further education, it is prudent that a conducive environment is created to enable students adapt and conform to their personal, academic and institutional expectations. It was therefore recommended that host institutions of these female students put in structures and interventions tailored towards the needs of these unique students to enable them manage their multiple identities and become successful learners as well.

\section{References}

Adu-Yeboah, C. (2011). Constructing higher education experiences through narratives: Selected cases of mature underground women students in Ghana (Doctoral thesis). Retrieved from http://sro.sussex.ac.uk/

Babbie, E., \& Mouton, J. (2001). The practice of social science research. Oxford, England: Oxford University Press.

Biddle, B. J. (1979). Role theory: Expectations, identities, and behaviors. Retrieved from www.annualreviews.org

Bosch, B. (2013). Women who study: Balancing the dual roles of graduate student and mother (Doctoral thesis). Retrieved from http://ro.ecu.edu.au/theses/592/

Creswell, J. W. (2012). Educational research: Planning, conducting, and evaluating quantitative and qualitative research $\left(4^{\text {th }}\right.$ ed.). Retrieved from http://doi.org/10.1017/CBO97811074153

Dalla, R. L., MoulikGupta, P., Lopez, W. E., \& Jones, V. (2006). "It's a balancing act!": Exploring school/work/family interface issues among bilingual, rural Nebraska, paraprofessional educators. Family Relations, 55, 390-402.

Fairchild, E. E. (2003). Multiple roles of adult learners. New Directions for Student Services, 2003(102), 11-16. http://doi.org/10.1002/ss.84

Filipponi-Berardinelli, J. O. (2013). Exploring efficacy in negotiating support: Women re-entry students in higher education. College Quarterly, 16(2). Retrieved from http://files.eric.ed.gov/fulltext/EJ1016456.pdf

Flick, U. (2014). An introduction to qualitative research (5th ed.). London: Sage.

Gilligan, C (1982). In a different voice: Psychological theory and women's development. Cambridge: Harvard University Press.

Goode, W. J. (1960). A theory of role strain. Am. Sociol. Rev. 25, 483-96.

Hemmerich, A. (2014). Persistence factors for adult women learners at a Northeast Community College. Education Student Publications, (Paper 5). Retrieved from http://scholarworks.merrimack.edu/soe_studentpub/5.

Keith, P. (2007). Barriers and nontraditional students' use of academic and social services. College Student Journal, 41(4), 1123-1127.

Lincoln, Y., \& Guba, E. (1985). Naturalistic inquiry. Beverly Hills, CA: Sage.

Lowe, J., \& Gayle, V. (2007). Exploring the work/life/study balance: The experience of higher education students in a Scottish further education college. Journal of Further and Higher Education, 31(3), 225-238. http://doi.org/10.1080/03098770701424942

Marsman, J. (2014). Between a rock and a hard place: Role dissonance in female non-traditional students. College Student Affairs Leadership, 1(1), Article 4. Retrieved from http://scholarworks.gvsu.edu/csal/volı/iss1/4 
McCune, V., Hounsell, J., Christie, H., Cree, V. E., \& Tett, L. (2010). Mature and younger students' reasons for making the transition from further education into higher education. Teaching in Higher Education, 15(6), 691-702. http://doi.org/10.1080/13562517.2010.507303

McKnight, A. (2015). Downward mobility, opportunity hoarding and the 'glass floor'. London: Social Mobility and Child Poverty Commission.

Mudhovozi, P. (2011). College adaption experiences of married female undergraduate students : An exploratory study. Journal of Psychology in Africa, 21(3), 465-468. http://doi.org/10.108o/14330237.2011.10820483

Mwangi. A. W. (2018). Determinants of changing gender roles amoong the Maasai women living in Ngong Town, Kajiado, Kenya. (Master thesis). Retrieved from http://ir-library.ku.ac.ke/handle/123456789/10956.

Ogletree, S. M. (2014). Gender role attitudes and expectations for marriage. Journal of Research on Women and Gender, 5, 71-82. Retrieved from http://www.tdl.org

O'Shea, S., \& Delahunty, J. (2018). Getting through the day and still having a smile on my face! How do students define success in the university learning environment? Higher Education Research and Development 37(5), 1062-1075.

Panacci, A. G. (2015). Adult students in higher education: Classroom experiences and needs. College Quarterly, 18(3), 1-18.

Pare, E. R. (2009). Mother and student: The experience of mothering in college (Unpublished doctoral dissertation). Wayne State University, Detroit MI.

Plageman, P. (2011). Adult women in higher education: The perceived influence of families (Doctoral thesis). Retrieved from https://etda.libraries.psu.edu/paper/11655/6725

Powell, G. N., \& Greenhaus, J. H. (2010). Sex, gender, and the work-to-family interface: Exploring negative and positive interdependencies. Academy of Management Journal, 53, 513-534.

Quimby, J. L. \& O’Brien, K. M. (2006). Predictors of well-being among nontraditional female students with children. Journal of Counseling $\mathcal{E}$ Development, 84, 451-46o. http://doi.org/10.1002/j.15460566678.2006.tboo429.x

Ruderman, M. N., Ohlott, P. J., Panzer, K., \& King, S. N. (2002). Benefits of multiple roles for managerial women. Academy of Management Journal, 45(2), 369-386. http://doi.org/10.2307/3069352.

Sieber, S. D. (1974). Toward a theory of role accumulation. Am. Sociol. Rev.39, 567-78.

Spilovoy, T. M. (2013). Motherhood and the pursuit of higher education:A phenomenological study of college student mothers completing online bachelor's degree programs (Doctoral Dissertation). Retrieved from https://www.ben.edu

Somuah, B. A., Itegi, F. M., \& Kariuki, S. I. (2018). Financial roles and its effect on persistence of female students in distance education programmes in Ghana. The Turkish Online Journal of Distance Education, 19(4), $104-115$.

Tight, M. (2012). Researching higher education (2 ${ }^{\text {nd }}$ ed.). Berkshire, England: Society for Research into Higher Education and Open University Press.

White, S. (2008). Mothers who are student teachers: Navigating their dual roles in pre-service teacher education. Studies in Continuing Education, 30 (2), 159-172.

White, S. (2009). Mothers becoming teachers. What motivates them? What doesn't? International Journal of Inclusive Education, 13(1), 79-92. 